\title{
FURTHER NOTES UPON THE ANALYSIS AND COMPOSITION OF BUTTER-FAT.
}

By William Johnstone, Ph.D., F.I.C., F.C.S.

IN the June number of the ANALYST of 1889 , I roughly described a method whereby the soluble and insoluble fatty acids of a butter-fat could easily be determined with accuracy, and since the publication of that paper the correctness of the process has been confirmed by the independent researches of Messrs. Bondzynski and Rufie, and recorded by them in the Zeitschr. Annal. Chem. (29.1-6).

Since the publication of my previous paper I have introduced several improvements in the various manipulations, and the process is now carried out as follows :-

The butter-fat is carefully claritied and saponified with a known quantity of standard alkali. The saponification is carried out in the following manner. Instead of saponifying in a closed flask as previously stated, and which required to be repeatedly shaken, I now carefully weigh out 2.5 grams. into a stout glass tube with flat bottom 
( 7 inches high and $2 \frac{1}{2}$ inches wide), practically a narrow, strong beaker, then add 2 ozs. of 95 per cent. neutral alcohol and 1 oz. of ether, and finally run in 25 c.c. of $\frac{\mathrm{N}}{\mathrm{NaHO}}$ solution, attach the tube to an upright condenser, and heat by means of a water-bath until saponification takes place, the time generally required being about one hour. When saponification is complete, the tube is removed from the condenser, $3 \mathrm{oz}$. of proof spirit added, and the titration immediately commenced, using phenolphalein as an indicator, the temperature of the soap solution being maintained at a temperature of between $80^{\circ}$ and $95^{\circ} \mathrm{F}$., the following being the actual figures obtained in three duplicate analysis operating in the above-described manner :-

\begin{tabular}{|c|c|c|c|c|c|c|}
\hline \multirow{2}{*}{$\begin{array}{l}\text { Fat taken } \\
\frac{\mathrm{N}}{\mathrm{NaHu}} \\
\mathrm{N}\end{array}$} & \multicolumn{2}{|r|}{$\underset{2 \cdot 5}{I .}$} & \multicolumn{2}{|r|}{$\begin{array}{l}\text { III. } \\
2 \cdot \tilde{5}\end{array}$} & \multicolumn{2}{|c|}{$\begin{array}{c}\text { Beef fat. } \\
2 \cdot 5\end{array}$} \\
\hline & $25 \cdot 00$ & $25 \cdot 00$ & $25 \cdot 00$ & $25 \cdot 00$ & 25.00 & 25.00 \\
\hline$\overline{\mathrm{H}_{2} \mathrm{SU}_{4}}$ added & $12 \cdot 00$ & $12 \cdot 00$ & 12.00 & 1200 & $12 \cdot 00$ & $12 \cdot 00$ \\
\hline $\mathrm{N}$ & & & & & & \\
\hline $\begin{array}{l}\overline{\mathrm{NaHU}} \text { consumed } \\
\text { Acid required to } \\
\text { complete titration } \\
\mathrm{N}\end{array}$ & $13 \cdot 00$ & $13 \cdot 00$ & $13 \cdot 00$ & $13 \cdot 00$ & 13.00 & $13 \cdot 00$ \\
\hline$1 0 \longdiv { \mathrm { H } _ { 2 } \mathrm { SO } _ { 4 } }$ & $14 \cdot 90=1 \cdot 49$ & $15 \cdot 00=1 \cdot 50$ & $10 \cdot 90=109$ & $10 \cdot 60=1.06$ & $2460=246$ & $24 \cdot 30=2 \cdot 43$ \\
\hline $\mathrm{N}$ & & & & & & \\
\hline $\begin{array}{l}\text { Total NaHu consumed } \\
\text { Average }\end{array}$ & $11 \cdot 51$ & $11.50^{11.50}$ & $11 \cdot 91$ & 11.94 & $10 \cdot 54$ & $\begin{array}{r}10.57 \\
10 . \div 6\end{array}$ \\
\hline
\end{tabular}

Working in this manner, an accurate estimation of the amount of alkali required for saponification is obtained, and from which the Koettstorfer number of the fat is readily calculated. The titration of the alcoholic soap solution requires, as stated, to be made at a temperature of between $80^{\circ}$ and $90^{\circ}$, otnerwise results are obtained which at present I do not venture to account for, but simply record them until I have time to fully investigate the cause, as it is apparently not due to dissociation as is ordinarily accepted, as otherwise we should have more alkali consumed at $90^{\circ} \mathrm{F}$. than at $60^{\circ} \mathrm{F}$., whereas we have more consumed at $60^{\circ} \mathrm{F}$. than at $90^{\circ} \mathrm{F}$. Thus :-

Butter-fat taken

Alkali taken $\frac{\mathrm{N}}{\mathrm{NaHO}}$

Acid added $\frac{\mathrm{N}}{\mathrm{H}_{2} \mathrm{SO}_{4}}$
$2 \cdot 5$ grms.

$\begin{array}{llll}25 \cdot 00 & 25 \cdot 00 & 25 \cdot 00 & 25 \cdot 00 \\ \frac{12 \cdot 00}{13.00} & \frac{12 \cdot 00}{13 \cdot 00} & \frac{12 \cdot 00}{13 \cdot 00} & \frac{12 \cdot 00}{13 \cdot 00}\end{array}$

Acid required to complete titration $10 \frac{\mathrm{N}}{\mathrm{H}_{2} \mathrm{SO}_{4}}$

Total alkali consumed at $60^{\circ}$ F... . . . .

$$
6 \cdot 20=\underline{0 \cdot 62}
$$

$12 \cdot 38$

$$
6.50=\underline{0.65}
$$

$$
640=\underline{0.64}
$$$$
6 \cdot 60=0.66
$$

$12 \cdot 35$

\section{$12 \cdot 34$}

The above, upon standing a few minutes, begin to show alkaline reaction, and deposit a precipitate of fatty acids, the solution at the same time evolving a continuous stream of small bubbles; if the solutions are now heated in the water-bath to a tem- 
perature of $90^{\circ} \mathrm{F}$., the precipitate that has formed redissolves, and the following quantity of acid is required to again render the solution neutral, which, upon standing any length of time, remains clear and also neutral.

Total alkali required at $60^{\circ} \mathrm{F}$

$12 \cdot 38$

$12 \cdot 35$

$12 \cdot 36$

1234

Acid required at $20^{\circ} \mathrm{F} .10 \frac{\mathrm{N}}{\mathrm{H}_{2} \mathrm{SO}_{4}} \quad 3 \cdot 42=\frac{0.34}{12 \cdot 04} \quad 3 \cdot 20=\frac{0.32}{12.03} \quad 3 \cdot 20=\frac{0.32}{12.04} \quad 3 \cdot 30=\frac{0.33}{12.01}$

Average of $\frac{\mathrm{N}}{\mathrm{NaHO}}$ at $60^{\circ} \mathrm{F}$.
$\quad " \quad, \frac{\mathrm{N}}{\mathrm{NaHO}}$ at $90^{\circ} \mathrm{F}$.

$12 \cdot 03$

1202

$11 \cdot 92$

$11 \cdot 92$

Difference between the two estimations ..

Beef-fat, or similar triglycerides, do not behave in the above-described manner.

After the titration is completed, the alcoholic soap solution is carefully washed into a porcelain basin, the alcohol evaporated off, excess of acid added so as to decompose the soap, then gently heated until the fatty acids are melted.

The insoluble fatty acids are now filtered off through an unweighed filter in the usual manner, thoroughly washed with boiling water until the washings are neutral, when the filter containing them is set aside in a moderately warm place and allowed to air dry. When the filter is sufficiently dry, it is transferred to a Soxhlet extractiontube, and thoroughly extracted with $d r y$ ether, the acids being received in an acuratelyweighed flask of sufficient capacity, so as to allow the ultimate titration of the insoluble fatty acids to be made in the same flask; the washing out of the insoluble fatty acids with alcohol from the extraction-flask now becomes unnecessary. When the extraction is complete, the ether is evaporated off, and the flask and contents are placed in the water-oven, and when dry, allowed to cool and finally weighed. Thus :-

\begin{tabular}{|c|c|c|c|c|c|c|c|c|}
\hline \multicolumn{3}{|c|}{ Insoluble fatty acids and flask } & $32 \cdot 4376$ & $28 \cdot 3180$ & 324500 & $29 \cdot 0433$ & $27 \cdot 3704$ & $\begin{array}{l}29 \cdot 5244 \\
27 \cdot 1613\end{array}$ \\
\hline Flask & . & . & $30 \cdot 2942$ & $26 \cdot 1744$ & $30 \cdot 2948$ & $26 \cdot 8856$ & $25 \cdot 0144$ & $27 \cdot 1613$ \\
\hline Insoluble & acids & of & & & & & & \\
\hline $\begin{array}{l}2 \cdot 5 \text { grms. } \\
+40=\text { per ce }\end{array}$ & $\begin{array}{l}. \\
.\end{array}$ & 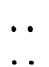 & $\begin{array}{c}2 \cdot 1434 \\
85 \cdot 736\end{array}$ & $\begin{array}{l}2 \cdot 1436 \\
85 \cdot 744\end{array}$ & $\begin{array}{c}2 \cdot 1552 \\
86 \cdot 208\end{array}$ & $\begin{array}{r}2 \cdot 1577 \\
86 \cdot 308\end{array}$ & $\begin{array}{r}2 \cdot 3560 \\
94 \cdot 240\end{array}$ & $\begin{array}{r}2 \cdot 3631 \\
94 \cdot 524\end{array}$ \\
\hline Average $\ldots$ & $\begin{array}{l}\cdots \\
\cdots\end{array}$ & $\cdots$ & 85 & & 80 & 25 & & 38 \\
\hline
\end{tabular}

When the percentage of insoluble fatty acids have been ascertained, add sufficient normal alkali to the flask, heat gently, when saponification rapidly takes place; then add 3 oz. of 85 per cent. alcohol, and titrate again with standard acid, and estimate the amount of alkali now consumed by the insoluble fatty acids, from which the Koettstofer number of the insoluble fatty acids can be calculated. Thus :-

\begin{tabular}{|c|c|c|c|c|c|c|}
\hline$\overline{\mathrm{NaHO}}$ taken & $12 \cdot 00$ & $12 \cdot 00$ & $12 \cdot 00$ & $12 \cdot 00$ & 1200 & 12.00 \\
\hline$\overline{\mathrm{H}_{2} \mathrm{DO}_{4}}$ required & $38 \cdot 0=3 \cdot 80$ & $38 \cdot 4=3 \cdot 84$ & $34 \cdot 60=3 \cdot 46$ & $33 \cdot 60=3 \cdot 36$ & $14 \cdot 54=1 \cdot 45$ & $14 \cdot 70=1 \cdot 47$ \\
\hline Avera & $8 \cdot 20$ & $8 \cdot 18$ & 854 & 8.59 & 10.55 & 10.54 \\
\hline
\end{tabular}




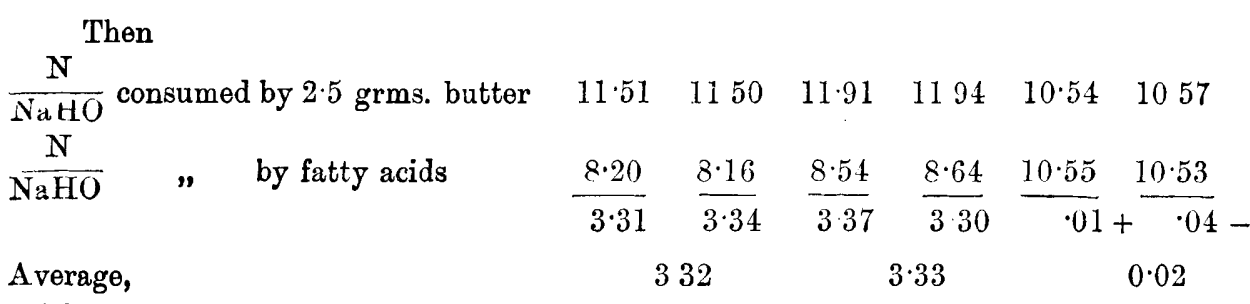

$\frac{\mathrm{N}}{\mathrm{NaHO}}$ required by soluble fatty acids of 2.5 grms. of butter-fat calculated into $\mathrm{C}_{4} \mathrm{H}_{8} \mathrm{O}_{2}$.

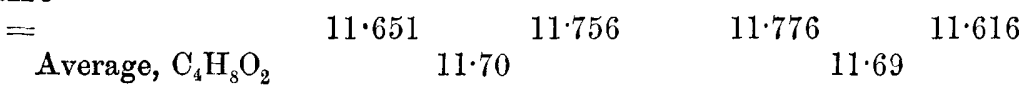

Working in the manner indicated, we obtain an accurate estimation of the total soluble and unsoluble fatty acids contained in a butter-fat; as the accuracy of Koettstorfer's process has never been questioned, it stands to reason that if the saponification number can be accurately determined in the original fat, it can also be accurately determined in the insoluble fatty acid, and any difference between these two determinations must be due to soluble fatty acids.

The process as described is simple, rapid and accurate, only requiring ordinary care: No complicated apparatus or delicate reagents are necessary, such as those required for the Reichert Wollny process - a process which has been described by Mr. Otto Hehner (now the President of the Society of Public Analysts) as follows:- "Whatever comparative results Reichert's process was capable of furnishing, if always performed in the same. manner. Yet analysts should not on principle tolerate a process by which only a portion of the substance to be estimated was obtained; but in all cases where a rial and accurate estimation was possible, such rough and ready methods should not be admitted by careful analysts." In my previous paper I expressed some doubts as to the nature of the soluble volatile fatty acids; but from the results obtained in the following experiment all doubts in my mind upon that point has now been removed. Considerably over one pound of butterfat was saponified with $\mathrm{NaHO}$, the resulting soap decomposed, and the soluble fatty acids again neutralised with $\mathrm{NaHO}$ (after the separation of the insoluble fatty acids had been accomplished), and evaporated to crystallisation, the glycerine drained off, the salts redissolved in water and recrystallised, the crystals obtained being washed with a mixture of alcohol and ether (two parts of 90 per cent. alcohol and one part of ether) to remove any adhering glycerine and water, and then air-dried.

The purified crystals were then placed in a retort, water added to dissolve them, and finally $\mathrm{H}_{2} \mathrm{SO}_{4}$ added, and distillation conducted by means of an oil bath, until vapours of $\mathrm{H}_{2} \mathrm{SO}_{4}$ began to appear in the retort.

The distillate obtained was neutralised by $\mathrm{BaH}_{2} \mathrm{O}_{2}$ solution, and then a current of $\mathrm{CO}_{2}$ passed through the solution, which was afterwards heated, and finally filtered. A portion of the liquid was then evaporated on the water-bath, to dryness, and finally dried at $260^{\circ} \mathrm{F}$., thus-

Barium salt dried at $260^{\circ}$ F. + Basin $\quad \ldots \quad 40 \cdot 2200$

$\begin{array}{lllllll}\text { Basin } \quad \ldots & \ldots & \ldots & \ldots & \ldots & 39 \cdot 8278\end{array}$

Amount of barium salt taken $\quad \ldots \quad \ldots \quad r 3922$ 
Redissolved in water and evaporated with dilute $\mathrm{H}_{2} \mathrm{SO}_{4}$, and again evaporated to dryness, and igniting gave

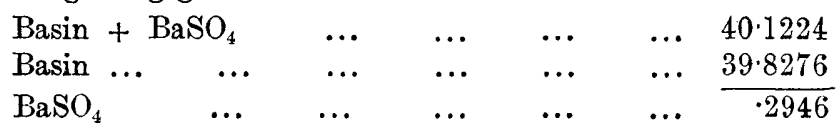

A 100 parts of the above barium salt yielding

A 100, $\mathrm{Ba}\left(\mathrm{C}_{4} \mathrm{H}_{7} \mathrm{O}_{2}\right)_{2} \quad$,

$75 \cdot 19$ per cent. $\mathrm{BaSO}_{4}$

74.92 per cent. $\mathrm{BaSO}_{4}$

Further research in this direction was not continued.

The glycerine and mother liquor obtained in purifying the barium salt was now examined for the possibility of it still containing a soluble non-rolatile fatty acid, but with negative results, as far as the investigation in this direction was carried.

I now directed my attention to the volatile fat acid which collects in the condenser when a Reichert Wollny test is being made. Some of the fat thus collected was dissolved in 95 per cent. neutral alcohol, and then carefully neutralised with an alcoholic solution of $\mathrm{BaH}_{2} \mathrm{O}_{2}$, which caused a heavy white precipitate which was filtered off from the solution it was formed in, then carefully washed with alcohol and ether, and finally dried over sulphuric acid.

A portion of the barium aalt thus formed was taken and dissolved in dilute sulphuric acid, and evaporated to dryness in the water-bath, ignited and weighed, which gave the following results :-

Amount of barium salt taken $\quad=\cdot 2525$

Weight of $\mathrm{BaSO}_{4}$ produced from amount taken

A 100 parts of above barium salt yields $\mathrm{BaSO}_{4} \quad 48.39$
A 100,
" $\mathrm{Ba}\left(\mathrm{C}_{10} \mathrm{H}_{10} \mathrm{O}_{2}\right)_{2}$ " $\mathrm{BaSO}_{4}$
$48 \cdot 64$

Consequently the above result proves the fat collected in the condenser consists mostly of capric acid.

The results of the analysis of the two butters as given in this paper were obtained from June butters ; the first was received from Norfolk, the second from Ireland.

The insoluble fatty acids in both instances being the lowest I had ever obtained with correspondingly high soluble fatty acids, as butyric acid, and at the same time giving results unaccountable when reviewed as follows, I determined, if possible, to secure more of the butter for further examination, as there was no doubt whatever as to their genuineness, both samples being from private country dairies, the cows not being kept, in a commercial point of view, more than for domestic consumption of large private establishments.

$$
\begin{aligned}
& \text { Insoluble fatty acids } \quad \ldots \quad \ldots \quad \ldots \quad \ldots \quad 85 \cdot 74 \quad 86.25 \\
& \begin{array}{lllllll}
\text { Butyric acid... } & \ldots & \ldots & \ldots & \ldots & 11 \cdot 82 & 11 \cdot 69
\end{array} \\
& \begin{array}{llllllll}
\text { Glyceryl } & \cdots & \cdots & \cdots & \ldots & \cdots & \frac{5.82}{103.38} & \frac{6.03}{103.97}
\end{array}
\end{aligned}
$$

The above figures, however, are not correct as regards the glyceryl, as the glycerine has been very carefully estimated in duplicate by the well-known method of Messrs. Benedikt and Zsigmondy, and gave the following results :-

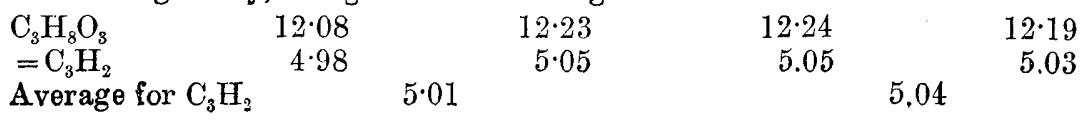


proving that the glyceryl cannot be correctly calculated in a butter-fat from its saponification equivalent.

I am now engaged upon the examination of the insoluble fatty acids when pressure of outside business does not interfere with same, and the results already obtained suggest to my mind the following explanation, namely, that there are two kinds of butter, one a compound tri-glyceride, giving insoluble fatty acids as low as 85.81 per cent., and onea mixture of two compound tri-glycerides, giving insoluble fatty acids up to 90 per cent. The first may be represented by this formula :-

$$
\left.\begin{array}{l}
\mathrm{C}_{18} \mathrm{H}_{33} \mathrm{O}_{2} \\
\mathrm{C}_{10} \mathrm{H}_{31} \mathrm{O}_{2} \\
\mathrm{C}_{10} \mathrm{H}_{10} \mathrm{O}_{2}
\end{array}\right\} \mathrm{C}_{3} \mathrm{H}_{5}=748 \text { At. Wt. }
$$

Iso-oleo-palmito-capriate of glycerine the first radicle having the following constitution :-

$$
\begin{array}{ll}
\mathrm{C}_{13} \mathrm{H}_{25} \mathrm{O} & \text { Iso-oleic acid } \\
\mathrm{CH}_{2} \mathrm{C}_{18} \mathrm{H}_{34} \mathrm{O}_{2}
\end{array}
$$

The iso-oleo-palmito-capriate of glycerine may be represented as follows :-

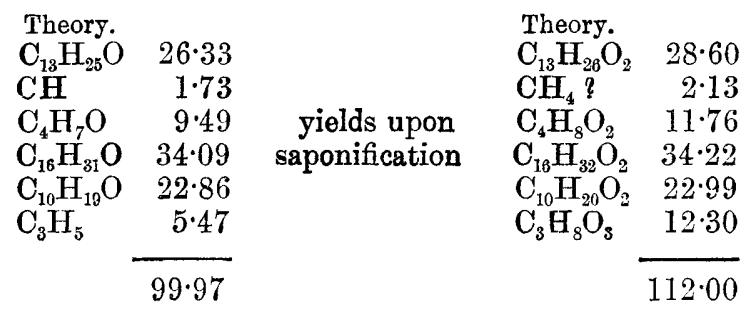

Found.

From the above formula it will be at once apparent that $I$ am assuming that a butter-fat yielding 85.81 per cent. of insoluble fatty acids is a tri-glyceride wherein the first radicle of the tri-acid compound is a compound acid of the formula $\left.\begin{array}{l}\mathrm{C}_{13} \mathrm{H}_{25} \mathrm{O} \\ \mathrm{C}_{4} \mathrm{H}_{7} \mathrm{O}\end{array}\right\} \mathrm{CH}_{2}$ (iso-oleic-acid ?) tridecatoic methane butyrate, the second radicle being palmitic acid, and the third radicle capric acid, forming a molecule of butter-fat.

When a compound such as tridecatoic methane butyrate is saponified with an alkali in 95 per cent. alcohol, the following equation may be taken as representing the change which takes place, thus :-

$$
\begin{aligned}
& \mathrm{C}_{18} \mathrm{H}_{34} \mathrm{O}_{2}+3 \mathrm{NaHO}=\mathrm{C}_{13} \mathrm{H}_{25} \mathrm{NaO}_{2}+\mathrm{C}_{4} \mathrm{H}_{7} \mathrm{NaO}_{2}+\mathrm{CH}_{3} \mathrm{NaO}+\mathrm{H}_{2} \\
& \text { Iso-oleic- Sodium Sodium Sodium Sodium } \\
& \text { acid. hydrate. tridacotic. butyrate. methylate. Hydrogen. }
\end{aligned}
$$

The second butter spoken of is a mixture of the above tri-glycerine with tri-nondecatoic acid. Thus :-

$$
\left.\begin{array}{l}
\mathrm{C}_{18} \mathrm{H}_{33} \mathrm{O}_{2} \\
\mathrm{C}_{16} \mathrm{H}_{31} \mathrm{O}_{2} \\
\mathrm{C}_{10} \mathrm{H}_{19} \mathrm{O}_{2} \\
\mathrm{C}_{19} \mathrm{H}_{37} \mathrm{O}_{2} \\
\mathrm{C}_{19} \mathrm{H}_{33} \mathrm{O}_{2} \\
\mathrm{C}_{7} \mathrm{H}_{14} \mathrm{O}_{2}
\end{array}\right\} \mathrm{C}_{3} \mathrm{H}_{5}
$$

Of course, I advance the above theory with all due reservation, but from the results obtained I think I am warranted in advancing it, the correctness of which, of 
course, will be proved when a closer examination of the insoluble fatty acids have been made an investigation, which $I$ have now well in hand, and the results already obtained in that direction are so far favourable to supporting it. The two samples of butter-fat at present under examination are so very much alike in composition that $I$ shall now draw your attention to the three samples of butter-fat mentioned in the June number of the ANALYST of 1889 , and then the difference between these samples when viewed by this theory immediately became apparent. If the $\mathrm{C}_{4} \mathrm{H} \mathrm{O} \mathrm{O}_{2}$ found is calculated into the iso-oleo-palmito-capriate of glycerine we get the following results :-

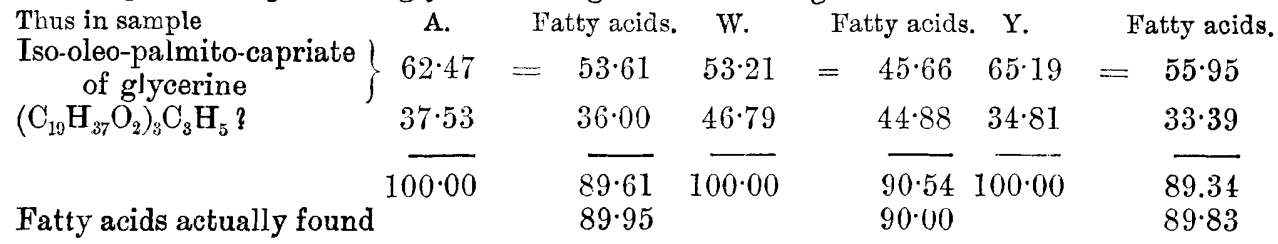

It now becomes apparent that the radicle of œnanthylic acid might replace one of nondecatoic acid in the tri-glyceride, and form the di-nondecatoic cenanthylic of glycerine, which apparently is the case in sample marked $\mathrm{W}$, for when calculated as di-nondecatoic œnanthylic the insoluble fatty acids came to $90 \cdot 12$ against $90 \cdot 00$ found ; a result well within the limit of error, as the process has been rendered more accurate since the temperature was taken into consideration, and which was previously not considered of so much importance. The difference between the amount of iso-oleo-palmitocapriate of glyceride and $100 \mathrm{I}$ put down as tri-glyceride of nondecatoic acid (as I have results which point to such being the case) the following peculiarity will be observed, namely, that starting with butyric acid we have every fourth acid of the series in butterfat up to nondecatoic.

In concluding this paper, I add the following detail, obtained from the butters mentioned in this investigation, so that they may bo also put on record :-

\begin{tabular}{|c|c|c|c|c|c|c|}
\hline C & & $\begin{array}{c}\text { A. } \\
907 \cdot 80\end{array}$ & $\begin{array}{c}\text { W. } \\
904 \cdot 74\end{array}$ & $\begin{array}{c}\mathbf{Y} \\
.906 \cdot 63\end{array}$ & $\stackrel{\text { I. }}{.913 .85}$ & $\begin{array}{c}\text { II. } \\
.912 \cdot 96\end{array}$ \\
\hline elt & & $36 \cdot 5^{\circ} \mathrm{C}$ & $36.5^{\circ} \mathrm{C}$ & $36.0^{\circ} \mathrm{C}$ & $308^{\circ} \mathrm{C}$ & $31 \cdot 2^{\circ} \mathrm{C}$ \\
\hline at $15 \cdot 5^{\circ} \mathrm{C}$ & & 96335 & 96349 & 96325 & 797.58 & $797 \cdot 66$ \\
\hline idy & & $41 \cdot 5^{\circ} \mathrm{C}$ & $41.5^{\circ} \mathrm{C}$ & $41 \cdot 0^{\circ} \mathrm{C}$ & $38 \cdot 3^{\circ} \mathrm{C}$ & $8.5^{\circ}$ \\
\hline
\end{tabular}

Since writing the above an unexpected confirmation of the amount of butyric acid contained in a butter yielding 85.80 per cent. of insoluble fatty acids has turued up.

I find from my laboratory nute-book that on the 3rd February, 1887, I received a sample of butter which gave 85.80 per cent. of insoluble fatty acids, and had the following specific gravity and melting point :-

$$
\text { Sp. gr. at } 378^{\circ} \mathrm{C} \quad 913.83 \quad \text { Melting point. } 29 \cdot 4^{\circ} \mathrm{C} \text {. }
$$

A portion of this butter, 39971 grame, were saponified with lime in a flask, 100 c.c. of water containing phosphoric acid added, and then 500 c.c. of water, and then 500 c.c. distilled. The addition of the 500 c.c. and distillation was repeated five consecutive times, the last 200 c.c. coming over perfectly neutral; the varioun distillates were then titrated, and gave volatile acid calculated as $\mathrm{C}_{4} \mathrm{H}_{8} \mathrm{O}_{2}$.

$\begin{array}{lcc}1 & \text { Distillate } & 3 \cdot 845 \\ 2 & \text { " } & 3 \cdot 192 \\ 3 & " & 2425 \\ 4 & " & 1 \cdot 210 \\ 5 & " & 1 \cdot 100\end{array}$

Total $\mathrm{C}_{4} \mathrm{H}_{8} \mathrm{O}_{2} \quad 11 \cdot 772$ against theoretical $7 \cdot 76$ 
The subject is one which has up to the present been beset with great difficulties, so I have ventured to record a few preliminary results, for if I might so write this investigation is merely in its infancy; a large amount of tedious and laborious work will require to be undertaken before $I$ can thoroughly establish tho correctness of my theory, consequently I have been induced to advance the same in its embryo in the hope that others with more leisure than myself may be enticed to investigate the subject in the direction indicated, and help to solve the question of butter analysis, as it certainly is in a most unsatisfactory state at present. 